\title{
IATROGENIC MANIA WITH DULOXETINE: AN EMERGING PRESCRIPTION ERROR
}

Harsh Chalana ${ }^{1}$, Jasmine Kaur Sachdeva² ${ }^{2}$ Tanu Kundal ${ }^{3}$, Amandeep Singh Malhari ${ }^{4}$

\section{HOW TO CITE THIS ARTICLE:}

Harsh Chalana, Jasmine Kaur Sachdeva, Tanu Kundal, Amandeep Singh Malhari. "Iatrogenic Mania with Duloxetine: an Emerging Prescription Error". Journal of Evolution of Medical and Dental Sciences 2014; Vol. 3, Issue 18, May 05; Page: 4795-4798, DOI: 10.14260/jemds/2014/2514

ABSTRACT: Introduction: Duloxetine is an SNRI (selective serotonin norepinephrine reuptake inhibitor) class of drug widely used as an antidepressant. There is no doubt about its potential role in musculoskeletal pain but its indiscriminate use by physicians has probably started showing its dark side. CASE REPORTS: We present 3 case reports with manic symptoms with Duloxetine for condition other than Major Depression. DISCUSSION: While using Duloxetine, risk benefit ratio should be considered as mania may be a less common adverse effect but its seriousness cannot be undermined. CONCLUSION: A cautious approach is needed by physicians while prescribing Duloxetine.

KEYWORDS: Duloxetine, mania, drug induced.

INTRODUCTION: Duloxetine is an SNRI (selective serotonin norepinephrine reuptake inhibitor) class of drug widely used as an antidepressant. It has also been widely publicized as a pain killer by parent manufacturing and marketing companies, especially in somatic and neuropathic pains. There is no doubt about its potential role in such conditions other than depression but its indiscriminate use by non-psychiatrists has probably started showing its dark side. A pooled data by Dunner et al. $(2005)^{5}$ showed that the estimated risk of Duloxetine related manic switching is $0.1 \%$ to $0.2 \%$ in patients with major depression.

However, he also concluded that diagnostic diligence on the part of the investigators was a methodological limitation of the study, which leads us to interpret that the actual risk of manic switching with Duloxetine still remains unknown. According to Viktrup et al. (2004)9 , Duloxetine does not induce mania or hypomania in women with stress urinary incontinence and without a history of depression.

Carta et al. (2006) $)^{2}$ found a high frequency of manic symptoms in a sample of female patients with fibromyalgia attending a rheumatology outpatient Unit. According to Duloxetine's summary of product characteristics, mania is a rare side effect. However, we present 3 case reports about patients who had been prescribed Duloxetine by physicians for condition other than Major Depression and presented to psychiatry outpatient with manic symptoms.

\section{CASE REPORTS:}

Case 1: A 37 year old male presented with manic symptoms for past 15 days. He had been advised Tablet Duloxetine $20 \mathrm{mg} /$ day increased to $40 \mathrm{mg}$ /day in 1 week along with a combination tablet of Aceclofenac $100 \mathrm{mg}$, Paracetamol $325 \mathrm{mg}$ and Chlorzoxazone $500 \mathrm{mg}$ (in b.d. dosage) for his complaint of low backache for past 3 weeks by an orthopaedician. There was no apparent deformity in his spine $\mathrm{x}$-ray.

He did not have any past history of depression or mania nor did he have any mood symptoms while presenting to orthopaedician. There was history of occasional alcohol intake, up to 30-60 ml, 
once or twice a month but he was abstinent for past 3 weeks. No other history of substance abuse, head injury, or co-morbid medical illness was evident. His electrolytes and thyroid profile were normal. His YMRS (Young Mania Rating Scale) score was 17 on presentation to us.

Although the patient lacked insight and needed admission, his family members could not afford it. So, it was planned to manage him on an outpatient basis. His Duloxetine was stopped and he was started on Lorazepam $2 \mathrm{mg}$ h.s. for his sleep. On day 7, his YMRS score was 15, which was not a significant reduction. He was then started on Tablet Olanzapine $5 \mathrm{mg}$ b.d. His YMRS score improved to 6 on day 21 and was 0 on day 35. He has been followed up since then and has been stable for past 6 months on Olanzapine $5 \mathrm{mg}$ h.s.

Case 2: A 45 year old female on conservative treatment (neck collar, NSAIDS combination, muscle relaxants) by another orthopaedician for her diagnosis of cervical spondylosis was started on Duloxetine $20 \mathrm{mg} /$ day for her ongoing muscle pain and stiffness. She showed mild improvement in her neck symptoms in 3 weeks but shifted to hypomania after only 1 week of onset of Duloxetine.

She was referred to psychiatry department for her decreased sleep and irritable behaviour at 3 weeks. Her YMRS was 11 at that point and had overconfidence, ideas of grandiosity, and over activity. There was no past history of psychiatric morbidity. Her Duloxetine was stopped and was put on Clonazepam $0.5 \mathrm{mg}$ h.s. On day 20, she showed significant improvement with YMRS score of 1 . Her Clonazepam was then gradually tapered off. She was followed up for next 2 months during which she remained euthymic.

Case 3: A 35 year old male was on treatment from a medical specialist for his complaints of vague body aches. He was earlier on Pregabalin $150 \mathrm{mg} / \mathrm{d}$ and Methylcobalamin combination with moderate improvement in his symptoms. A high dose of Duloxetine $60 \mathrm{mg} /$ day was added to it but with no further improvement. However, he showed manic symptoms after 10 days of Duloxetine augmentation, with YMRS of 29.

On reviewing history during presentation to psychiatry department for his manic symptoms, his family members reported past history of 2 manic episodes, $1^{\text {st }} 7$ years and $2^{\text {nd }} 3$ years back for which he was treated by a psychiatrist, and was currently not on any psychotropics for past 1 year. He was admitted in psychiatry ward and managed with Sodium Valproate $1000 \mathrm{mg} / \mathrm{d}$, Risperidone 3 $\mathrm{mg} / \mathrm{d}$, and Lorazepam $4 \mathrm{mg} / \mathrm{d}$. He improved in next 20 days with YMRS of 14 at day 7 and 3 at day 20. He was then discharged with regular bimonthly follow-ups.

DISCUSSION: SNRIs have been reported to show efficacy in somatic pains (Brannan et al., 2005) ${ }^{1}$, musculoskeletal pain, phantom limb pain (Chalana, 2010) ${ }^{4}$, fibromyalgias (Carta et al., 2006) ${ }^{2}$, chronic fatigue, headache, spine related aches, stress incontinence, etc. Duloxetine is being used for indications like Diabetic peripheral neuropathic pain, Fibromyalgia, chronic musculoskeletal pain, and stress urinary incontinence, apart from depression and generalized anxiety disorder.

Brannan et al. (2005) ${ }^{1}$ showed that improvement in pain severity with Duloxetine was independent of changes in depressive symptom severity, but was effective only for the painful physical symptoms which are frequently associated with depression.

The pain inhibitory action of Duloxetine is believed to be a result of potentiation of descending inhibitory pain pathways within the central nervous system. It weakly inhibits dopamine 
reuptake also apart from inhibiting serotonin and norepinephrine reuptake. Use of Duloxetine may be considered polypharmacy in itself due to its effect on a range of neurochemicals and brain receptors. While using these molecules, risk benefit ratio should be considered as mania may be a less common adverse effect but its seriousness cannot be undermined.

As in case 1 above, although there was no past psychiatric history but starting Duloxetine as a first line analgesic proved to be more harmful than its potential benefit. Probably, only main stream NSAIDS, physiotherapy, heat therapy, or even opioids should have been preferred by orthopaedician rather than Duloxetine as a $1^{\text {st }}$ line agent. In case 2, though other options had been tried prior to augmentation with Duloxetine and as patient had no past history of mood disorder, its use seems to be rational and worth trial. But, it is important to be able to identify early symptoms of significant adverse events while using any drug.

There was a delay of about 2 weeks before referral, during which her manic symptoms worsened. She should have been monitored closely for her adverse reaction with Duloxetine. Case 3 shows inadequate history exploration before starting Duloxetine. Patient was a known case of bipolar disorder and starting an antidepressant without a mood stabilizer is not considered safe as it has a tendency to shift the patient to mania (Taylor D. et al., 2012) 8 .

He had a severe recurrence of $3^{\text {rd }}$ episode of mania and had to be hospitalized. According to Peritogianis et al. (2009)7 switching appears to be dose related and treatment initiation with lower doses and upward titration when needed may be preferable in selected cases and may help minimizing the risk of mood switching. In case 3, a dose of $60 \mathrm{mg}$ was started. It would have been more rational to gradually increase the dose.

CONCLUSION: A cautious approach is needed by physicians while prescribing Duloxetine. Almost all antidepressants have been reported with tendency to shift to mania as an adverse effect (Taylor D. et al., 2012) ${ }^{8}$. There is no reason why Duloxetine should be undermined (Feras et al., 2010 6; Consuelo\& Elena, 2007 3). A careful past history for bipolarity, manic episodes, depressive episodes, positive family psychiatric history and history of substance abuse should be taken prior to prescribing Duloxetine or any other antidepressant, especially prior to advising it for frivolous indications. More suitably, an expert psychiatric consult should be taken and a cautious follow up should be done. Duloxetine should not be treated at par with pain killers, as promoted by drug companies.

Rather, more suitable options which have strong evidence support may be chosen over it, like Tramadol, Pregabalin, Gabapentin, physiotherapy, etc. Moreover, awareness about symptoms of mania and early identification is also important for physicians who wish to use it. Weekly monitoring with any screening scale such as YMRS, and family education regarding early symptoms of mania can be of a help, if use of Duloxetine in non-depression indications appear to be advantageous and necessary. Further, more research is needed and a retrospective case control study would be of significance in establishing the iatrogenic manic shift potential of Duloxetine.

\section{REFERENCES:}

1. Brannan S K, Mallinckrodt CH, Brown EB, Wohlreich MM, Watkin J G, Schatzberg A F.. Duloxetine $60 \mathrm{mg}$ once-daily in the treatment of painful physical symptoms in patients with major depressive disorder. J Psychiatr Res. Jan 2005. 39(1):43-53. 
2. Carta MG, Cardia C, Mannu F et al. The high frequency of manic symptoms in fibromyalgia does influence the choice of treatment? Clin Pract Epidemol Ment Health. 2006; 2:3.

3. Consuelo de Dios, Elena Ezquiaga. Manic Switching in Patients Receiving Duloxetine. Am J Psychiatry. 2007;164:1121.

4. Chalana H. A case report of Milnacipran in phantom-limb pain. Asian J Psychiatr.Sep 2010;3(3):155-6.

5. Dunner D, D'Souza D, Kajdask D et al. Is treatment - associated hypomania rare with duloxetine: secondary analysis of controlled trials in non-bipolar depression. J Affective Disord. 2005; 87:115-9.

6. Feras A. Mustafa, Nadim Almoshmosh, Husni Al-Robb, and SuheibAbuKmeil. A Case of Possible Duloxetine-Induced Mania. German J Psychiatry. 2010; 13:54-6.

7. Peritogiannis V, Antoniou K, Mouka V et al. Duloxetine induced hypomania: case report and brief review ofthe literature on SNRIs-induced mood switching. JPsychopharmacol.2009.;23: 592-6.

8. Taylor D., Paton C., Kapur S. Bipolar Disorder, in: The Maudsley Prescribing guidelines in psychiatry. Eleventh edition. Wiley-Blackwell. 2012. pp.187-8

9. Viktrup L, Perahia D, Tylee A. Duloxetine treatment of stress urinary incontinence in women does not inducemania or hypomania. Prim Care Companion JClin Psychiatry. 2004; 6:239-43.

\section{AUTHORS:}

1. Harsh Chalana

2. Jasmine Kaur Sachdeva

3. Tanu Kundal

4. Amandeep Singh Malhari

\section{PARTICULARS OF CONTRIBUTORS:}

1. Associate Professor, Department of Psychiatry, Shri Guru Ramdas Institute of Medical Sciences \& Research, Amritsar, India.

2. Assistant Professor, Department of Medicine, Shri Guru Ramdas Institute of Medical Sciences \& Research, Amritsar, India.

3. Senior Resident, Department of Psychiatry, Shri Guru Ramdas Institute of Medical Sciences \& Research, Amritsar, India.
4. Psychologist, Department of Psychiatry, Shri Guru Ramdas Institute of Medical Sciences \& Research, Amritsar, India.

\section{NAME ADDRESS EMAIL ID OF THE CORRESPONDING AUTHOR:}

Dr. Harsh Chalana, Department of Psychiatry, Shri Guru Ramdas Institute of Medical Sciences \& Research, Vallah, Amritsar, India.

E-mail: harsh_chalana@yahoo.co.in

Date of Submission: 17/03/2014. Date of Peer Review: 18/03/2014. Date of Acceptance: 25/03/2014. Date of Publishing: 30/04/2014. 